\title{
Compression neuropathy of the peroneal nerve secondary to a ganglion cyst
}

\author{
Rebecca J Greer-Bayramoglu BSc ${ }^{1,2}$, André S Nimigan BSc MD ${ }^{1,2}$, Bing Siang Gan MD PhD FRCSC FACS $1,2,3,4,5$
}

\begin{abstract}
RJ Greer-Bayramoglu, AS Nimigan, BS Gan. Compression neuropathy of the peroneal nerve secondary to a ganglion cyst. Can J Plast Surg 2008;16(3):181-183.

Peripheral neuropathies caused by ganglion cysts are rare, particularly in the lower extremities. The case of a 45-year-old man with a twomonth history of foot drop and swelling in the region of the right fibular head is presented. Physical examination and electromyogram studies verified a peroneal nerve palsy. Magnetic resonance imaging revealed a lobulated, multilocular, cystic-appearing mass extending around the fibular neck. Surgical decompression of the nerve with removal of the mass and careful articular branch ligation was performed. Surgical pathology reports confirmed the diagnosis of a ganglion cyst. The patient regained full function within four months of the decompression. Pertinent findings on physical examination are discussed, as well as electromyogram and magnetic resonance imaging results. If symptoms persist, early surgical decompression (between the third and fourth months) is recommended.
\end{abstract}

Key Words: Foot drop; Ganglion cyst; Peripheral neuropathy; Peroneal nerve compressions

anglion cysts occur frequently and are considered to be the

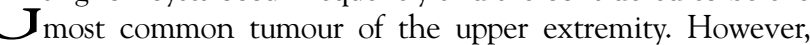
despite their high incidence, ganglia rarely result in peripheral nerve compression. In the upper extremity, in rare circumstances, ganglia have been described to cause compression of the ulnar nerve by a ganglion in Guyon's canal (1) or in the cubital tunnel (2) or of the median nerve at the carpal tunnel (3). Compression neuropathies of the lower extremity are much less common and only a handful of cases have been described in the surgical literature since the first description of a neuropathy of the peroneal nerve by Sultan in 1921 (4). This may be due to a referral bias in which patients presenting with lower extremity nerve deficits are more frequently sent to a neurologist rather than a surgeon. In the present report, we describe a patient with a ganglion cyst as a rare cause of peroneal palsy and foot drop treated surgically.

\section{CASE PRESENTATION}

A 45-year-old male truck driver presented to his family doctor with a two-month history of foot drop and tenderness in the region of the right fibular head, with gradual development of swelling in the area. Careful physical examination revealed soft swelling in the area below the fibular head. There was weakness in foot eversion and dorsiflexion, particularly of the great toe. Foot inversion was normal.

The patient was sent for electromyogram (EMG) studies, which demonstrated denervation potentials of the right tibialis anterior and extensor digitorum longus muscles. The diagnosis

\section{Neuropathie par compression du nerf péroné consécutive à un kyste ganglionnaire}

Les neuropathies périphériques causées par des kystes ganglionnaires sont rares, particulièrement au niveau des membres inférieurs. Les auteurs présentent ici le cas d'un homme de 45 ans présentant une chute du pied depuis deux mois et une enflure à la région de la tête du péroné. L'examen physique et l'électromyogramme ont confirmé une paralysie du nerf péroné. L'imagerie par résonance magnétique a révélé une masse d'aspect kystique lobulée et multiloculaire s'étendant autour du col du péroné. Une décompression chirurgicale du nerf avec ligature soigneuse du rameau articulaire ont été réalisées. Les rapports anatomopathologiques du spécimen reséqué ont confirmé le diagnostic de kyste ganglionnaire. Le patient a entièrement récupéré en l'espace de quatre mois suivant la décompression. Le présent article aborde les éléments pertinents de l'examen physique, de même que les résultats de l'électromyogramme et de l'imagerie par résonance magnétique. Si les symptômes persistent, une décompression chirurgicale précoce (entre le troisième et le quatrième mois) est recommandée.

\footnotetext{
${ }^{1}$ Hand and Upper Limb Centre, St Joseph's Health Centre; Departments of ${ }^{2}$ Plastic and ${ }^{3}$ Orthopedic Surgery, ${ }^{4}$ Physiology and Pharmacology, and

${ }^{5}$ Medical Biophysics, University of Western Ontario, London, Ontario

Correspondence: Dr Bing Siang Gan, Hand and Upper Limb Centre, St Joseph's Health Centre, Suite D0-215,

268 Grosvenor Street, London, Ontario N6A 4L6. Telephone 519-646-6097, fax 519-646-6049, e-mail bsgan@rogers.com
} 


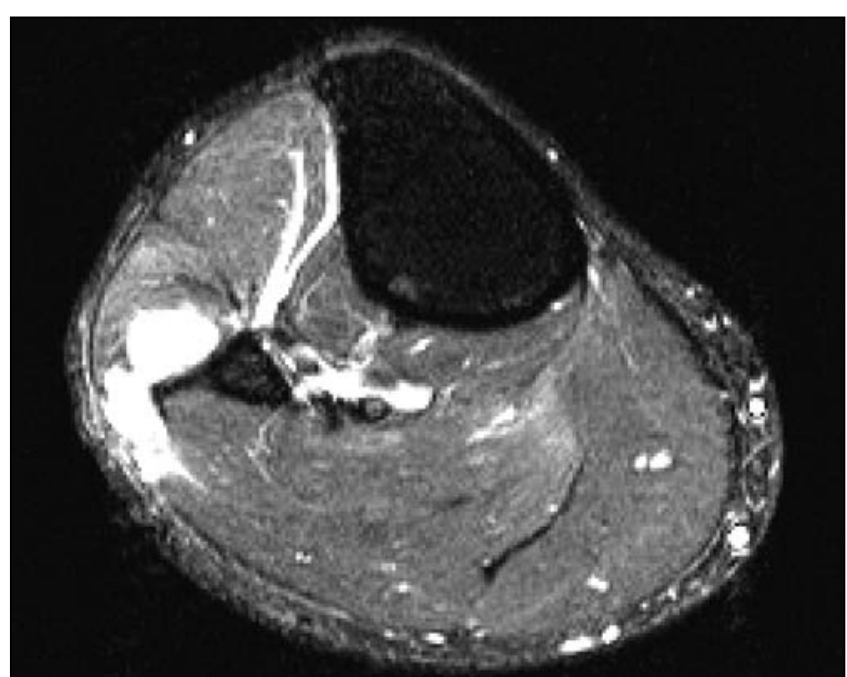

Figure 1) Characteristic magnetic resonance imaging findings of ganglion cyst with high signal intensity on the (T2-like) Inversion Recovery sequence images

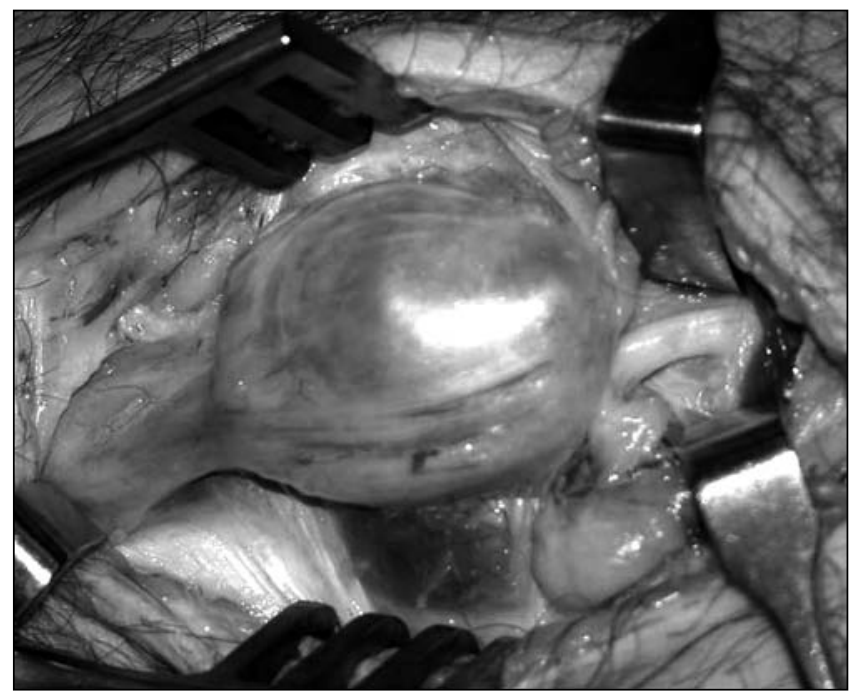

Figure 2) Intraoperative photograph of the lesion as seen associated with the peroneal nerve

articular branches to the knee and proximal tibiofibular joint, were cauterized using bipolar cautery. The mass measured approximately $3.0 \mathrm{~cm} \times 2.0 \mathrm{~cm} \times 2.0 \mathrm{~cm}$ and followed the anterior periosteum down to the deep corner of the anterior compartment. It was followed down to its stalk and removed in toto (Figure 3). The peroneal nerve was inspected and found to be completely intact. The surgical pathology report confirmed the diagnosis of a ganglion cyst. Four months after surgery, the patient had regained full function and had no complaints of pain.

\section{DISCUSSION}

While palsies of the peroneal nerve caused by ganglia are uncommon (5), they do occur, and expeditious treatment is important. The anatomy of the peroneal nerve is a direct set up for injury. The common peroneal nerve is derived from L4, L5, S1 and S2 as a division of the sciatic nerve $(6,7)$. The nerve becomes most vulnerable at its entrance to the fibular tunnel,

\section{PRECISION DYNAMICS CORP.}

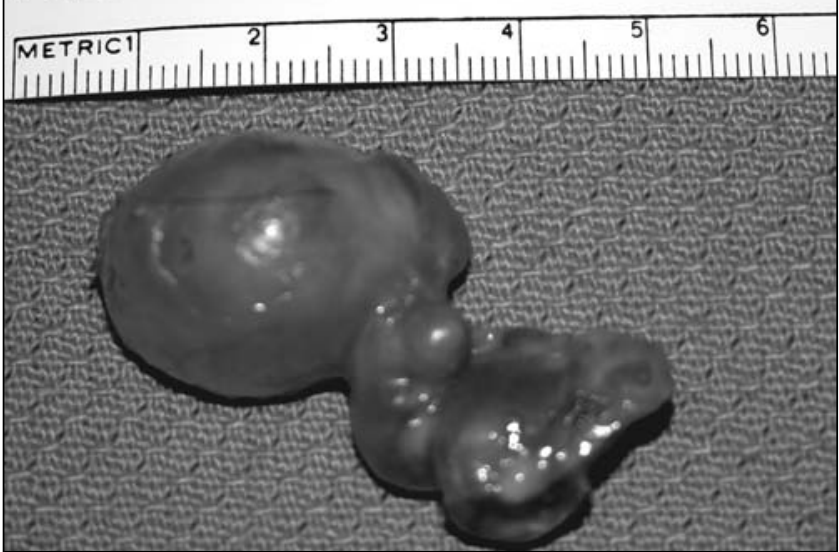

Figure 3) Ganglion completely excised from peroneal nerve compression site

where it courses superficial to the lateral surface of the fibula just distal to the fibular head (8). This superficial location gives the nerve little soft tissue protection. Mont et al (9), in a review of 31 patients receiving operative decompression for a peroneal nerve palsy, describe bands of fibrous tissue constricting the peroneal nerve at this level. This could further increase the nerve's susceptibility to compression.

A review of the literature supplies an extensive list of etiologies for peroneal nerve palsies. The list includes prolonged squatting or leg crossing $(10,11)$, chronic low grade infection (12), varicose veins (13), rapid marked weight reduction (14), schwannoma (15), nerve herniation through a fascial defect (16), giant plexiform neurofibromatosis (17), pneumatic compression (18), total knee arthroplasty (9), proximal tibial osteotomy (9) and ganglion cysts (19), to name a few.

Some of the palsies caused by ganglia present with no palpable mass (5), complicating accurate diagnosis. In peroneal nerve lesions at the region of the knee or distal thigh, patients often complain of altered ambulation secondary to paretic or paralyzed ankle dorsiflexors. A steppage gait pattern is common, wherein the affected foot requires extra lift from the ground during the swing phase of ambulation to clear the foot. While pain is not universal, when present, it is often related to the specific site of the common peroneal nerve compression.

On examination, sensory testing often shows a loss in the cutaneous distribution of the superficial and deep peroneal nerves. Tinel's sign is generally positive in the sensory distribution of the peroneal nerve. The muscles supplied by the common peroneal nerve are the tibialis anterior, the extensor hallucis longus, the extensor digitorum longus and brevis, and the peroneus longus and brevis (8). When isolating these muscle groups for testing, variable weakness is often found. The extensor digitorum brevis is the most profoundly affected. The tibialis anterior can also be significantly affected with weakness in ankle and toe dorsiflexion. Often, ankle eversion is normal, because patients can have relative sparing of these muscles. In a pure common peroneal neuropathy, plantar flexion should be spared.

Prompt follow-up of a suspicious case with diagnostic tests is important; several reports stress that full recovery requires expeditious treatment $(9,20-22)$. An EMG study may be helpful to 
correlate clinical findings by distinguishing the extent of sensory and motor impairment. MRI is the technique of choice for diagnostic imaging because it demonstrates excellent soft tissue contrast, and can provide multiplanar images (23). MRI is noninvasive, and allows the lesion to be located and the distribution of the muscles supplying the peroneal nerve to be analyzed. Delineating the extent of the mass, and the impairment of the nerve, is important in surgical planning. Ganglia characteristically present with low signal on T1-weighted images and high signal on T2-weighted images (24).

Currently, the accepted treatment for a peroneal nerve palsy due to a peripheral nerve ganglion is surgical removal of the ganglion $(5,20,21,23,25,26)$. Fabre et al (8) reported on 60 patients with peroneal nerve palsies, many idiopathic, who were treated with operative decompression. Postoperative recovery of motor function was good to excellent in $87 \%$ of those who had both sensory and motor involvement preoperatively. Decompression is recommended even for patients presenting with only sensory symptoms, if the symptoms have been substantiated by electrophysiological studies. We recommend open decompression of the peroneal nerve between the third and fourth months if symptoms persist or recovery is incomplete. Because of the extensive branching pattern of the peroneal nerve in the area of the fibular head, we believe that

\section{REFERENCES}

1. Erkin G, Uysal H, Keles I, Aybay C, Ozel S. Acute ulnar neuropathy at the wrist: A case report and review of the literature. Rheumatol Int 2006;27:191-6.

2. Strickland JW, Steichen JB. Nerve tumors of the hand and forearm. J Hand Surg [Am] 1977;2:285-91.

3. Kerrigan JJ, Bertoni JM, Jaeger SH. Ganglion cysts and carpal tunnel syndrome. J Hand Surg [Am] 1988;13:763-5.

4. Sultan C. Ganglion der Nervenscheide des Nervus Peroneus. Zentralblatt fur Chirurgie 1921;48:963-5.

5. Ramelli GP, Nagy L, Tuncdogan E, Mathis J. Ganglion cyst of the peroneal nerve: A differential diagnosis of peroneal nerve entrapment neuropathy. Eur Neurol 1999;41:56-8.

6. Ducic I, Dellon AL, Graw KS. The clinical importance of variations in the surgical anatomy of the superficial peroneal nerve in the mid-third of the lateral leg. Ann Plast Surg 2006;56: 635-8.

7. Ryan W, Mahony N, Delaney M, O’Brien M, Murray P. Relationship of the common peroneal nerve and its branches to the head and neck of the fibula. Clin Anat 2003;16:501-5.

8. Fabre T, Piton C, Andre D, Lasseur E, Durandeau A. Peroneal nerve entrapment. J Bone Joint Surg Am 1998;80:47-53.

9. Mont MA, Dellon AL, Chen F, Hungerford MW, Krackow KA, Hungerford DS. The operative treatment of peroneal nerve palsy. J Bone Joint Surg Am 1996;78:863-9.

10. Yilmaz E, Karakurt L, Serin E, Güzel H. [Peroneal nerve palsy due to rare reasons: A report of three cases]. Acta Orthop Traumatol Turc 2004;38:75-8.

11. Sangwan SS, Marya KM, Kundu ZS, Yadav V, Devgan A, Siwach RC. Compressive peroneal neuropathy during harvesting season in Indian farmers. Trop Doct 2004;34:244-6.

12. Schulze J, Troeger H. [Fibular nerve compression due to an unusual cause. A case report]. Handchir Mikrochir Plast Chir 2004;36:25-8.

13. Yamamoto N, Koyano K. Neurovascular compression of the common peroneal nerve by varicose veins. Eur J Vasc Endovasc Surg 2004:28:335-8.

14. Shahar E, Landau E, Genizi J. Adolescence peroneal neuropathy associated with rapid marked weight reduction: Case report and literature review. Eur J Paediatr Neurol 2007;11:50-4.

15. Mahitchi E, Van Linthoudt D. [Schwannoma of the deep peroneal nerve. An unusual presentation in rheumatology]. Praxis (Bern 1994) 2007;96:69-72. needle aspiration carries a substantial risk for nerve damage. In addition, the high risk of recurrence of a ganglion following needle aspiration probably predicts less favourable outcomes.

The most common complication of surgical ganglion removal is local recurrence. Rawal et al (20) hypothesized that the origin of peroneal nerve ganglia is the proximal tibiofibular joint, via the articular branch. Several papers report on local cyst recurrence postoperatively, and stress the importance of articular branch ligation to avoid this complication (21,24,26-28). Simple excision of the ganglia is not sufficient. Careful surgical planning and proper delineation of the mass is vital in identifying its origin. Other complications include traction injuries and perineural fibrosis with incomplete return of function. Less commonly, nerve transection occurs, leading to permanent dysfunction.

\section{CONCLUSION}

When a peroneal nerve palsy is suspected, proper history and physical examination, followed by prompt investigation by EMG and MRI are important. Diagnosis of a ganglion cyst should lead to early surgical excision between the third and fourth months, with careful attention to ligation of the articular branch. Careful preoperative planning and good surgical technique can result in a full recovery.

16. Yang LJ, Gala VC, McGillicuddy JE. Superficial peroneal nerve syndrome: An unusual nerve entrapment. Case report. J Neurosurg 2006;104:820-3.

17. Cebesoy O, Tutar E, Isik M, Arpacioglu O. A case of isolated giant plexiform neurofibroma involving all branches of the common peroneal nerve. Arch Orthop Trauma Surg 2007;127:709-12.

18. Fukuda H. Bilateral peroneal nerve palsy caused by intermittent pneumatic compression. Intern Med 2006;45:93-4.

19. Dallari D, Pellacani A, Marinelli A, Verni E, Giunti A. Deep peroneal nerve paresis in a runner caused by ganglion at capitulum peronei. Case report and review of the literature. J Sports Med Phys Fitness 2004;44:436-40.

20. Rawal A, Ratnam KR, Yin Q, Sinopidis C, Frostick SP. Compression neuropathy of common peroneal nerve caused by an extraneural ganglion: A report of two cases. Microsurgery. 2004;24:63-6.

21. Rein S, Weindel S, Schaller HE, Mittelbronn M, Schmidt G. [Peroneal nerve palsy caused by a recurrent proximal tibiofibular joint ganglion - a case report and review of the literature]. Handchir Mikrochir Plast Chir 2005;37:267-75.

22. Anselmi SJ. Common peroneal nerve compression. J Am Podiatr Med Assoc 2006;96:413-7.

23. Kim JY, Ihn YK, Kim JS, Chun KA, Sung MS, Cho KH. Nontraumatic peroneal nerve palsy: MRI findings. Clin Radiol 2007;62:58-64

24. Iverson DJ. MRI detection of cysts of the knee causing common peroneal neuropathy. Neurology 2005;65:1829-31.

25. Yamazaki H, Saitoh S, Seki H, Murakami N, Misawa T, Takaoka K. Peroneal nerve palsy caused by intraneural ganglion. Skeletal Radiol 1999;28:52-6.

26. Dubuisson AS, Stevenaert A. Recurrent ganglion cyst of the peroneal nerve: Radiological and operative observations. Case report. J Neurosurg 1996;84:280-3.

27. Khairallah E W, Weinberg MJ, Mahoney J. Acute common peroneal nerve palsy caused by hemorrhage into a recurrent ganglion. Can J Plast Surg 1995;3:209-12.

28. Spinner RJ, Atkinson JL, Scheithauer BW, et al. Peroneal intraneural ganglia: The importance of the articular branch. Clinical series. J Neurosurg. 2003;99:319-29. 